\title{
Failed peripheral nerve reconstruction with processed nerve allografts in three patients
}

\section{Nietosvaara, Yrjana}

2019-03

Nietosvaara , Y , Grahn , P \& Sommarhem , A 2019 , ' Failed peripheral nerve reconstruction with processed nerve allografts in three patients ' , Journal of Hand Surgery (European Volume) , vol. 44 , no. 3 , pp. 318-320 . https://doi.org/10.1177/1753193418817968

http://hdl.handle.net/10138/313085

https://doi.org/10.1177/1753193418817968

unspecified

publishedVersion

Downloaded from Helda, University of Helsinki institutional repository.

This is an electronic reprint of the original article.

This reprint may differ from the original in pagination and typographic detail.

Please cite the original version. 
Table 1. Demographic and injury details.

\begin{tabular}{|c|c|c|c|c|c|}
\hline & Case 1 & Case 2 & Case 3 & Case 4 & Case 5 \\
\hline Patient age & 16 & 53 & 49 & 52 & 50 \\
\hline Sex & $\mathrm{F}$ & $M$ & $\mathrm{~F}$ & $\mathrm{~F}$ & $\mathrm{~F}$ \\
\hline MOI & Knife wound & Shark attack & Knife wound & $\begin{array}{l}\text { Elbow } \\
\text { arthroscopy }\end{array}$ & Knife wound \\
\hline Injured nerve & PIN & Median & PIN & PIN & PIN \\
\hline Location of defect & Mid-forearm & Distal forearm & $\begin{array}{l}\text { Proximal } \\
\text { forearm }\end{array}$ & $\begin{array}{l}\text { Proximal } \\
\text { forearm }\end{array}$ & $\begin{array}{l}\text { Proximal } \\
\text { forearm }\end{array}$ \\
\hline Defect distance & $1.5 \mathrm{~cm}$ & $2.5 \mathrm{~cm}$ & $2 \mathrm{~cm}$ & $2 \mathrm{~cm}$ & $2.5 \mathrm{~cm}$ \\
\hline $\begin{array}{l}\text { Time taken for } \\
\text { recovery of } \\
\text { motor function }\end{array}$ & 5 months & $\begin{array}{l}6 \text { months for } \\
\text { motor ( } 4 \\
\text { months for } \\
\text { sensation) }\end{array}$ & 8 months & 6 months & 7 months \\
\hline $\begin{array}{l}\text { Motor function at } \\
\text { recovery }\end{array}$ & M4 & M4 & M3 & M4 & M4 \\
\hline Sensory function & $\mathrm{N} / \mathrm{A}$ & $\begin{array}{l}5 \text { to } 10 \mathrm{~mm} \text { on } \\
\text { two-point } \\
\text { discrimination }\end{array}$ & $\mathrm{N} / \mathrm{A}$ & $\mathrm{N} / \mathrm{A}$ & $\mathrm{N} / \mathrm{A}$ \\
\hline $\begin{array}{l}\text { Return of pro- } \\
\text { tective SRN } \\
\text { sensation }\end{array}$ & 10 months & 12 months & 12 months & 10 months & 6 months \\
\hline
\end{tabular}

MOI: mechanism of injury; PIN: posterior interosseous nerve; SRN: superficial radial nerve.

Declaration of conflicting interests The authors declared no potential conflicts of interest with respect to the research, authorship, and/or publication of this article.

Ethical approval Office for Research Governance \& Development; Gold Coast Hospital and Health Service.

HREC Ref: HREC/17/QGC/152.

SSA Reg: SSA/17/QGC/156.

\section{References}

Laing T, Siddiqui A, Sood M. The management of neuropathic pain from neuromas in the upper limb: surgical techniques and future directions. Plas Aesth Res. 2015, 2: 165-70.

Lee YH, Chung MS, Gong HS, Chung JY, Park JH, Baek GH. Sural nerve autografts for high radial nerve injury with nine centimeter or greater defects. J Hand Surg Am. 2008, 33: 83-6.

Lundborg G, Rosen B. Hand function after nerve repair. Acta Physiol (Oxf). 2007, 189: 207-17.

Slutsky DJ. A practical approach to nerve grafting in the upper extremity. Atlas Hand Clin. 2005, 10: 73-92.

Ganesh Balendra ${ }^{1, *}$, Jonathan Quinn ${ }^{1}$ and Randy Bindra ${ }^{1,2}$

${ }^{1}$ Gold Coast University Hospital, Southport, QLD, Australia

${ }^{2}$ Griffith University, Southport, QLD, Australia

*Corresponding author: ganesh.balendrala

health.qld.gov.au
(C) The Author(s) 2018

Article reuse guidelines:

sagepub.com/journals-permissions

doi: $10.1177 / 1753193418796753$ available online at http://jhs.sagepub.com

\section{Failed peripheral nerve reconstruction with processed nerve allografts in three patients}

Dear Sir,

Repair of peripheral nerve injuries with segmental loss is challenging, partly because the amount of available nerve autograft is limited. Processed nerve allografts (PNAs) have recently been reported to perform well in sensory, mixed and motor defects between $5-50 \mathrm{~mm}$, with a meaningful recovery rate of 76-100\% (Brooks et al., 2012; Cho et al., 2012; Means et al., 2016). We present three patients treated with PNA Avance ${ }^{\circledR}$ Nerve graft (AxoGen Inc., FL, USA) with poor results owing to resorption of the PNA. Written consent was obtained from all patients/parents. The authors (surgeons conducting the surgery) have all attended AxoGen's nerve symposium: Advances and best practices in upper extremity repair. 
Case 1. A healthy 41-year-old man had a laceration of the digital nerve at the proximal interphalangeal (PIP) joint level of his little finger. Treatment of the injury was delayed for 3 months owing to a wound infection, leading to a $35^{\circ}$ flexion contracture of the PIP joint as well as painful wound site hypersensitivity. After resection of volar scar tissue, full extension of the PIP joint was achieved. The cut ends of the nerve were revised under $3.5 \times$ loupe magnification to normal healthy looking, bleeding nerve tissue. The nerve gap was bridged, tension free, using a $20 \mathrm{~mm}$ Avance ${ }^{\circledR}$ Nerve graft of good size match. The repair was performed using two 9-0 Ethilon ${ }^{\circledR}$ sutures at each end, as well as $2 \mathrm{~mm}$ Connectors sutured in place. Tissee ${ }^{\circledR}$ (Baxter, IL, USA) fibrin glue was applied at both ends. Cefuroxime $1.5 \mathrm{~g}$ was administered intravenously during induction. A volar splint in the safe position was applied for 2 weeks. Three weeks post-operatively, a superficial wound infection was diagnosed and treated successfully with per-oral cephalexin. Extension of the PIP joint improved after the operation, but there was no improvement of the dysaesthesia, nor was any sensory recovery returned. In a re-operation performed 19 months after the primary surgery, the PNA was found to be resorbed and replaced by fibrous scar tissue. The defect was repaired with a vascularized nerve graft from the dorsum of the hand. At 14 months followup, the patient had gained some subjective sensory recovery, as well as some relief of the dysaesthesia of the operated finger.

Case 2. A 53-year-old female sustained an iatrogenic tibial nerve injury at the ankle level, which was explored 4 months later. The distal stump, as well as the proximal neuroma, were revised under $3.5 \times$ loupe magnification to bleeding normal-looking nerve tissue, leaving a $45 \mathrm{~mm}$ gap, which was bridged with a $50 \mathrm{~mm}$ Avance ${ }^{\circledR}$ Nerve graft of excellent size match. Neurorraphy was performed with 8-0 Ethilon ${ }^{\circledR}$ sutures and Evicel ${ }^{\circledR}$ (Ethicon Inc., NJ, USA) fibrin glue under microscope magnification. A circular soft cast ankle dressing was applied for 2 weeks. Her wound healed uneventfully, but no sensory nor motor recovery took place. Magnetic resonance imaging (MRI) performed 10 months after surgery showed normal-looking tibial nerve proximal to the grafting site, which then thickened into a neuromalike stump. She was offered a re-repair with autologous sural nerve grafts but declined further surgery.

Case 3. A boy born at 42 weeks of gestation sustained a total brachial plexus birth injury. A cervical MRI was performed at 13 days of age, which was suggestive of a $\mathrm{C} 8$ avulsion. His brachial plexus was explored at 5 weeks of age. He had a rupture of $\mathrm{C} 5$, $\mathrm{C} 6$ and $\mathrm{C} 7$ roots, but $\mathrm{C} 8$ and $\mathrm{T} 1$ were clinically intact.
The upper and middle trunks were reconstructed without tension with five $2 \times 20 \mathrm{~mm}$ Avance ${ }^{\circledR}$ Nerve grafts, which were secured in place with Evicel ${ }^{\circledR}$ fibrin glue. During induction he received $270 \mathrm{mg}$ of cefuroxime intravenously and a repeat dose 3 hours into the surgery, which lasted 6 hours. His wound healed uneventfully and there were no signs of infection. There was no recovery of shoulder movements or elbow flexion clinically, nor in electromyography performed 10 months after surgery. A re-operation was performed at 11 months of age, which revealed that all five PNA grafts had resorbed completely. A reconstruction of the patient's upper and middle trunks was performed with five $3.5-4.5 \mathrm{~cm}$ long autologous sural nerve grafts. One year after the re-operation, shoulder abduction was Grade 5 and elbow flexion Grade 2, as assessed by the Active Movement Scale.

PNA is an appealing option in the treatment of peripheral nerve injuries that require grafting, mainly because there is a limited supply of autologous nerve grafts. Second, donor site morbidity can be avoided using PNAs. In a multicentre study with $55 \%$ followup rate of peripheral nerve injuries treated with PNAs, $48 / 54$ patients reported a positive response to treatment and meaningful recovery in $87 \%$ of these patients. The criteria for meaningful recovery was defined as return of at least M3 motor and S3 sensory function by the Medical Research Council muscle strength and sensory recovery scale (Brooks et al., 2012). A study by $\mathrm{Cho}$ et al. (2012) found meaningful levels of recovery in $89 \%$ of digital nerve repairs, $75 \%$ of median nerve repairs, and $67 \%$ of ulnar nerve repairs in 51 of 56 adult patients, with PNA lengths varying between 5 to $50 \mathrm{~mm}$. The follow-up rate in this study is unclear, however.

Berrocal et al. (2013) reported a single case of failed PNA repair of ulnar nerve at wrist level. Their patient underwent re-exploration and excision of the 'regenerated cable', which demonstrated minimal axonal regeneration at the midpoint of the repair. The findings at re-exploration in our Patients 1 and 3 were similar to the findings in this report. In addition, our second patient had resorption of the PNA as evaluated by the post-operative MRI. The reason for resorption of the PNAs could at least partly be related to the wound infection in Case 1. One other possible explanation could be host rejection to the PNA, although according to the manufacturer, Avance ${ }^{\circledR}$ Nerve grafts are decellularized and therefore, should not cause an immune response.

PNA grafts should be used with caution in peripheral nerve reconstructions until the cause and the true frequency of resorption of the PNAs are thoroughly investigated. 
Declaration of conflicting interests The authors declared no potential conflicts of interest with respect to the research, authorship, and/or publication of this article.

Funding The authors received no financial support for the research, authorship, and/or publication of this article.

\section{References}

Berrocal YA, Almeida VW, Levi AD. Limitations of nerve repair of segmental defects using acellular conduits. J Neurosurg. 2013, 119: 733-8.

Brooks DN, Weber RV, Chao JD et al. Processed nerve allografts for peripheral nerve reconstruction: a multicenter study of utilization and outcomes in sensory, mixed, and motor nerve reconstructions. Microsurgery. 2012, 32: 1-14.

Cho MS, Rinker BD, Weber RV et al. Functional outcome following nerve repair in the upper extremity using processed nerve allograft. J Hand Surg Am. 2012, 37: 2340-9.

Means KR Jr, Rinker BD, Higgins JP, Payne SH Jr, Merrell GA, Wilgis EF. A multicenter, prospective, randomized, pilot study of outcomes for digital nerve repair in the hand using hollow conduit compared with processed allograft nerve. Hand (NY). 2016, 11: 144-51.

\section{Yrjänä Nietosvaara ${ }^{1,2,3}$, Petra Grahn ${ }^{1, *}$ and Antti Sommarhem ${ }^{1,2,3}$ \\ ${ }^{1}$ Department of Pediatric Orthopedics and Hand Surgery, Helsinki University Central Hospital, Helsinki, Finland ${ }^{2}$ Department of Surgery, Central Hospital of South Carelia, Lappeenranta, Finland \\ ${ }^{3}$ Aava Hospital, Helsinki, Finland *Corresponding author: petra.grahnahus.fi}

(C) The Author(s) 2018

Article reuse guidelines:

sagepub.com/journals-permissions

doi: 10.1177/1753193418817968 available online at http://jhs.sagepub.com

\section{latrogenic femur fracture following medial femoral condyle flap harvest eventually requiring total knee arthroplasty in one patient}

Dear Sir,

The medial femoral condyle free flap (MFC) is a corticoperiosteal vascularized flap used to address nonunion or bone loss (Higgins and Buerger, 2014). Previous reports have reflected minimal MFC donor site morbidity (Endara et al., 2015; Katz et al., 2012). One donor femur fracture has been reported within a case series and was treated with internal fixation (Hamada et al., 2014). We present a case of MFC harvest complicated by iatrogenic unicondylar femur fracture eventually requiring total knee arthroplasty.

A 61-year-old man presented with osteomyelitis of the left distal radius. After debridement he had a 3-cm metaphyseal defect. After osteomyelitis treatment, an MFC was used for reconstruction. The MFC was harvested using the previously described technique (Higgins and Buerger, 2014). After flap elevation, additional cancellous bone was harvested and packed around the radius osteosynthesis site. Intraoperatively, there was no fracture or compromise of the knee joint.

Two weeks later, he experienced sudden pain in his left knee when changing direction while walking. He did not sustain direct trauma. He presented with knee swelling and X-ray identified a fracture. Computed tomography (CT) confirmed a non-comminuted unicondylar femur fracture (Figure 1a and b). The fracture was treated closed and failed to heal. Eight months later, his nonunion was treated with plating and proximal tibial bone grafting, which failed to unite. The patient underwent total knee arthroplasty 3 years after MFC. His wrist recovery was without complication.

At 6.5-year follow-up, the patient's left wrist and knee were pain-free. Surgical sites demonstrated well-healed scars. Left knee range of motion (ROM) was 0 to $140^{\circ}$ without instability. Left wrist range of motion was $80^{\circ}$ pronation, $45^{\circ}$ supination, $26^{\circ}$ flexion, $47^{\circ}$ extension, $30^{\circ}$ ulnar and $8^{\circ}$ radial deviation. Left-hand grip strength was $33 \mathrm{~kg}$ compared to $37 \mathrm{~kg}$ with the right. Imaging showed osseous union. The Disabilities of the Arm, Shoulder, and Hand (DASH) score was 1.7, likely reflecting that the patient is content with his function even with strength and ROM limitations. The knee injury and osteoarthritis outcome score (KOOS) pain assessment was 100 , symptoms 89 , activities of daily living 97, extremity function 80 , and quality of life 100 . On femur CT volumetric assessment, the harvested bone represented $13.4 \%$ of distal femur volume. On axial view, depth of dissection (medial-to-lateral) was $4.2 \mathrm{~cm}, 61 \%$ of femur diameter $(6.9 \mathrm{~cm})$ at that level.

The MFC was $5.5 \mathrm{~cm}$ long $\times 3.2 \mathrm{~cm}$ wide. Larger harvests have been reported without morbidity. Additionally, biomechanical evaluations focusing on stability related to the cortical defect demonstrated no impairment of axial stability regardless of length harvested (Katz et al., 2012), and that not until flap harvest is greater than $7 \mathrm{~cm}$ long does torsion result in a higher frequency of fracture (Endara et al., 2015). Although the dimensions of this MFC were within acceptable parameters, subsequent harvest of cancellous bone expanded the defect depth (medial-to-lateral) past the intercondylar fossa. 